\title{
Silica nanoparticle-based dual imaging colloidal hybrids: cancer cell imaging and biodistribution
}

\author{
This article was published in the following Dove Press journal: \\ International Journal of Nanomedicine \\ 28 August 2015 \\ Number of times this article has been viewed
}

\author{
Haisung Lee' \\ Dongkyung Sung ${ }^{2}$ \\ Jinhoon $\mathrm{Kim}^{3}$ \\ Byung-Tae $\mathrm{Kim}^{3}$ \\ Tuntun Wang ${ }^{4}$ \\ Seong Soo A An \\ Soo-Won Seo ${ }^{6}$ \\ Dong Kee $\mathrm{Yi}^{4}$
}

'Molecular Diagnostics, In Vitro Diagnostics Unit, New Business Division, SK Telecom, ${ }^{2}$ Department of Life Sciences, Graduate School of Korea University, ${ }^{3}$ Interdisciplinary Graduate Program of Biomedical Engineering, School of Medicine, Sungkyunkwan University, Samsung Medical Center, ${ }^{4}$ Department of Chemistry, Myongji University, Seoul, ${ }^{5}$ Department of Bionanotechnology, Gachon Medical Research Institute, Gachon University, Seongnam, ${ }^{6}$ Medical Device Development Center, Daegu-Gyeongbuk Medical Innovation Foundation, Daegu, Republic of Korea

Correspondence: Soo-Won Seo Medical Device Development Center, Daegu-Gyeongbuk Medical Innovation Foundation, Daegu 706-0I0, Republic of Korea

Email soowon@dgmif.re.kr

Dong Kee Yi

Department of Chemistry, Myongji

University, Yongin, Gyeonggi-do I7058,

Republic of Korea

Email vitalis@myongji.ac.kr

\begin{abstract}
In this study, fluorescent dye-conjugated magnetic resonance (MR) imaging agents were investigated in T mode. Gadolinium-conjugated silica nanoparticles were successfully synthesized for both MR imaging and fluorescence diagnostics. Polyamine and polycarboxyl functional groups were modified chemically on the surface of the silica nanoparticles for efficient conjugation of gadolinium ions. The derived gadolinium-conjugated silica nanoparticles were investigated by zeta potential analysis, transmission electron microscopy, inductively coupled plasma mass spectrometry, and energy dispersive x-ray spectroscopy. MR equipment was used to investigate their use as contrast-enhancing agents in $\mathrm{T}_{1}$ mode under a $9.4 \mathrm{~T}$ magnetic field. In addition, we tracked the distribution of the gadolinium-conjugated nanoparticles in both lung cancer cells and organs in mice.
\end{abstract}

Keywords: dual bioimaging, MR imaging, silica colloid, T1 contrast imaging, nanohybrid

\section{Introduction}

Generated molecular images can reflect the molecular and metabolic pathways within cells. In particular, tracking biological progress in a physiological environment and detecting possible malfunctions has been advocated as a means of diagnosing disease in its early stages. One commercially important magnetic resonance (MR) enhancing material is tetra-azacyclododecane-tetraacetic acid (TTA) containing gadolinium $(\mathrm{Gd}){ }^{1}$ Moieties of TTA become paramagnetic by the interaction between the $d$-orbital of Gd and lone pairs of electrons in nitrogen. The carboxylic ions attached to a macrocyclic ligand can also interact with the Gd ions. It is important that these molecular imaging probes can selectively target specific cells or organs for accurate diagnosis and treatment. Surface-modified silica nanoparticles afford the feasibility of combining various functionalities onto the silica surface..$^{2-21}$ Moreover, they have good water wettability and low cytotoxicity for in vivo application. ${ }^{22}$ Cellular imaging agents must produce adequate real-time diagnostic images. ${ }^{23}$ Real-time dual mode analysis and cell tracking protocols have been studied. ${ }^{24-30}$ Ligand-decorated silica particles have been widely used as analytical and biosensing tools. ${ }^{31-40}$ Timely multi-functional MR imaging contrast-enhancing nanoparticles have been studied in biomedical applications. ${ }^{41-52}$

With the above in mind, we designed silica nanoparticles to have a dual imaging mode, ie, (MR) imaging and fluorescent optical imaging. Poly(ethylene glycol) (PEG) and PEG-containing block copolymers, with very flexible and hydrophilic properties, were conjugated onto the silica nanoparticles to enable them to escape uptake by the mononuclear phagocyte system. Qianjun et al reported that PEGylated nanoparticles reduce nonspecific binding of serum proteins and cellular responses. ${ }^{53}$ The silica nanoparticles were decorated further with Gd ions and fluorescent dye. The resulting functionalized silica (hereafter referred to as dual imaging silica) nanoparticles were 
characterized by transmission electron microscopy (TEM), energy-dispersive spectroscopy, dynamic light scattering (DLS), and optical imaging analysis. The particles were further investigated as potential MR imaging agents when studying $\mathrm{T}_{1}$ relaxivity and image-enhancing efficiency. Transfection of lung cells was implemented using lung cancer cells and the corresponding organ cell has been imaged under the multi-modal imaging such as fluorescence and magnetic resonance imaging. The distribution of these dual imaging silica nanoparticles to the organs after intraperitoneal injection was studied in a mouse model by elemental analysis using inductively coupled plasma mass spectrometry (ICPMS).

\section{Materials and methods Materials}

Most of the materials used in this study were obtained from commercial sources. Trimethoxy(3-[oxiran-2-ylmethoxy] propyl)silane (TPS), branched polyethylenimine (PEI, molecular weight 25,000), 4',6-diamidino-2-phenylindole (DAPI), $\mathrm{NaHCO}_{3}$, silica (LUDOX AS-40) nanoparticles, dichloromethane (DCM), $\mathrm{GdCl}_{3} \cdot 6 \mathrm{H}_{2} \mathrm{O}$, dimethyl sulfoxide, sodium sulfate $\left(\mathrm{Na}_{2} \mathrm{SO}_{4}\right)$, sulfonic acid sodium salt $97 \%$, ethyl acetate, rhodamine isothiocyanate (RITC), and hexane were obtained from Sigma-Aldrich. Mono-N-hydroxysuccinate (NHS)-PEG (molecular weight 5,000) was purchased from Sunbio Chem (Korea).

\section{Fabrication of dual imaging silica nanoparticles \\ Branching of mono-NHS-PEG and PEI}

A solution of mono-NHS-PEG $(50 \mathrm{mg}, 10 \mathrm{mmol})$ in anhydrous DCM (80 mL) was added to a solution of PEI (250 mg, 10 $\mathrm{mmol})$ in anhydrous DCM $(80 \mathrm{~mL})$ with cooling in an ice bath. The mixture was stirred at room temperature and the temperature was allowed to increase naturally from $0^{\circ} \mathrm{C}$ for 12 hours. Thin layer chromatography with ethyl acetate and hexane at a ratio of $1: 1(\mathrm{v} / \mathrm{v})$ was used to check the progress of the reaction. The solvent was evaporated by speed-vacuum and freeze-drying and the crude compound was kept in a freezer at $-20^{\circ} \mathrm{C}$. The crude solid material obtained after evaporation of the solvent was then purified by gel permeation chromatography (Sephadex LH20, $\mathrm{CH}_{2} \mathrm{Cl}_{2}$ ).

\section{Branching of PEG-PEI and TPS}

A solution of PEG-PEI (100 $\mathrm{mg}, 3.3 \mathrm{mmol})$ in DCM $(80 \mathrm{~mL})$ was added to a solution of TPS $(0.80 \mathrm{~mL}, 4.6 \mathrm{mmol})$ in the same solvent $(20 \mathrm{~mL})$ with cooling in an ice bath.
The mixture was stirred at room temperature; thereafter, the temperature was allowed to increase naturally from $0^{\circ} \mathrm{C}$ for 12 hours.

\section{Synthesis of PEI-PEG silica nanoparticles}

PEI-PEG (53 mg, $0.13 \mathrm{mmol}$ ) and TPS were placed in a round bottomed flask and dissolved with $1.25 \mathrm{~mL}$ of ethanol, $1.25 \mathrm{~mL}$ of water, and $1.25 \mathrm{~mL}$ of acetic acid. An aqueous suspension $(125 \mu \mathrm{L})$ of silica (LUDOX AS-40) nanoparticles (Sigma-Aldrich) was added. The reaction mixture was warmed to $80^{\circ} \mathrm{C}$ under stirring for 24 hours. The ethanol was evaporated under reduced pressure, and solid $\mathrm{NaHCO}_{3}$ was added to the suspension to reach a $\mathrm{pH} 7-8$. The precipitate was filtered and washed with a borate buffer solution $(\mathrm{pH} 9.5,5 \times 2 \mathrm{~mL})$ and with water $(5 \times 2 \mathrm{~mL})$. The solid was dried under vacuum and then redissolved in $100 \mathrm{~mL}$ of DCM. The organic solution was washed with water $(100 \mathrm{~mL})$ and dried over $\mathrm{Na}_{2} \mathrm{SO}_{4}$.

\section{Synthesis of RITC-labeled PEI-PEG silica nanoparticles}

A colloidal dispersion of PEI-PEG silica nanoparticles $(100 \mu \mathrm{g} / \mathrm{mL})$ was placed in a scintillation tube, and $5 \mathrm{mmol}$ RITC in dimethyl sulfoxide was added ( $\mathrm{pH} 7.7 \pm 0.3)$. The mixture was agitated for 12 hours at room temperature, and then cleaned in DCM. Finally, dialysis was carried out using a dialysis tube for 48 hours (molecular weight cutoff, $50 \mathrm{kDa}$ ).

\section{Synthesis of Gd (III)-PEI-PEG-RITC silica nanoparticles}

RITC-labeled PEI-PEG silica nanoparticles (5 mg) were placed in a round bottomed flask and deionized water was added to create a neutral $\mathrm{pH}$ condition. Additionally, a $\mathrm{GdCl}_{3}$ $(10 \mathrm{mM})$ solution was provided and vortexed for 12 hours at $90^{\circ} \mathrm{C}$. Arsenazo (III) solution was used with a colorimetric method to investigate binding between the Gd (III) ions and the PEI-PEG-RITC silica nanoparticles. The color of Arsenazo (III) solution changes to green when free Gd (III) ion are present in solution; further, the bright pink color of Arsenazo III solution changes to dark purple when Gd (III) ion become conjugated with certain ligands.

\section{Quantitative analysis of Gd (III) ions by ICPMS}

To verify the concentration of Gd in the purified complexes, ICPMS was performed using a computer-controlled Agilent 7500 device. Samples were prepared by digestion in nitric acid (ratio of nitric acid to sample, $9: 1$ ) in a $70^{\circ} \mathrm{C}$ water bath. 
The samples were diluted in $15 \mathrm{~mL}$ conical vials with a final concentration of $3 \%(\mathrm{v} / \mathrm{v})$ nitric acid. Gd (III) standards were purchased from AccuStandard (New Haven, CT, USA) and diluted to $0.1,1,5,10$, and $50 \mathrm{ng} / \mathrm{mL}$ of Gd (III). The samples were treated with $60 \% \mathrm{HNO}_{3}(1 \mathrm{~mL})$ and $35 \% \mathrm{HCl}(3 \mathrm{~mL})$, and then pre-processed and analyzed with ICPMS (300 W power, 130 psi pressure, and $70^{\circ} \mathrm{C}$ temperature).

\section{Dynamic light scattering}

The complexes were investigated by DLS for particle size and zeta potential using a Nano ZS instrument at $25^{\circ} \mathrm{C}$. An He-Ne laser producing vertically polarized light $\left(\lambda_{0}\right.$ approximately $632.8 \mathrm{~nm}$ ) was used as the light source. Each sample was filtered using a $0.2 \mu \mathrm{m}$ cellulose acetate membrane.

\section{Cell culture and transfection of PEI-PEG silica nanoparticles and RNA}

A549 (human alveolar basal epithelial) cells were sourced from the Korea Cell Line Bank (Seoul, Republic of Korea) and cultured in RPMI 1640 medium supplemented with $10 \%$ heat-inactivated fetal bovine serum and $1 \%$ antibiotics (Invitrogen, Grand Island, NY, USA) at $37^{\circ} \mathrm{C}$ in a humidified atmosphere of $5 \% \mathrm{CO}_{2}$. The cells were seeded in a 12 -well culture plate at a density of $2 \times 10^{5}$ cells per well and allowed to attach overnight. The incubation medium was then replaced by fresh medium. Dual imaging silica nanoparticles of different concentrations $(0.1-1 \mathrm{mg} / \mathrm{mL})$ were transferred into the wells by dropwise. After incubation for 4 hours, the old medium was replaced with fresh medium, and the nanoparticle-treated cells were incubated for 24 hours. The nucleus was stained with DAPI (blue) and the complex was represented with red for successful transfection of $\mathrm{Gd}(\mathrm{III})$ PEI-PEG-RITC-silica nanoparticles. Since A549 cell, human derived neuroblastoma cell, was commercially available, ethics was not sought.

\section{Animal experiments and animal care}

Normal SD mouse (20 g weight) was used and animal number was two (Central Lab Animal Inc, Seoul, Korea). First, $100 \mu \mathrm{L}$ of the dual imaging silica nanoparticle solution was injected slowly using a $1 \mathrm{~mL}$ syringe into the tail vein. Concentration of the dual imaging silica nanoparticle colloidal solution 100 $\mu \mathrm{L}(2 \mathrm{mg} / \mathrm{mL})$ was injected into the mice. The dual imaging silica nanoparticles were administered by intraperitoneal injection. The mice were euthanized using $\mathrm{CO}_{2}$ gas in the euthanasia chamber supplied by compressed gas cylinders. One hour later, the internal organs, including kidney, spleen, pancreas, heart, lungs, and liver, were removed from each animal. The organs were then fixed in 10\% formalin solution and investigated for distribution of Gd by ICPMS.

All animals were housed and maintained at $20^{\circ} \mathrm{C}-24^{\circ} \mathrm{C}$ on a 50:50 light-dark cycle. They received humane care in compliance with the Guide for the Care and Use of Laboratory Animals prepared by the Institute of Laboratory Animal Resources and published by the US National Institutes of Health and in accordance with the animal experiment guidelines of Samsung Biomedical Research Institute (SBRI). The study was reviewed and approved by the Institutional Animal Care and Use Committee of the SBRI. SBRI is a facility accredited by the Association for Assessment and Accreditation of Laboratory Animal Care International and abides by the Institute of Laboratory Animal Resources guidelines.

\section{Results and discussion}

The entire synthesis procedure is summarized in Figure 1. Branched PEI was PEGylated using amine and NHS conjugation chemistry. PEGylated PEI was conjugated onto silica nanoparticles via TPS. The PEI-PEG silica nanoparticles were investigated by solid-state nuclear magnetic resonance (NMR) (Figure S1). The particles were reacted further with RITC dye, and Gd was conjugated onto the particles via the polyamine group on the PEI (Figure 1). The morphological characteristics of the dual imaging silica nanoparticles were investigated by both DLS and TEM. The average particle size was $40 \pm 7 \mathrm{~nm}$ by DLS (Figure 2A) and TEM (Figure 2B). Moreover, elemental analysis by energy-dispersive spectroscopy (interfaced with TEM) showed that weight portion of ${ }^{64} \mathrm{Gd}$ was approximately $4.92 \%$ and that of ${ }^{29} \mathrm{Si}$ and ${ }^{8} \mathrm{O}$ was $48.85 \%$ and $46.23 \%$, respectively (Figure 2C-E).

The hydrophilic properties of silica nanoparticles and the multiple amine functionality grafts on the PEGylated PEI create an environment appropriate for enhancing MR imaging in $T_{1}$ mode. ${ }^{54}$ The hydrophobic surface moiety on the dual imaging silica could lead to it being captured and anchored in the liver, while the hydrophilic polar coating by which surface charges ${ }^{55}$ can prolong its retention in the circulation. ${ }^{56-59}$ Further, the surface amine groups on the dual imaging silica can chelate Gd ions and interact in an aqueous environment to produce T1-weighted MR images, with hydration on the dual imaging silica nanoparticles affecting the image contrast. It has been reported that relaxivity is dependent on the hydration environment of Gd conjugate's its number. ${ }^{59}$

Figure 3 shows that the dual imaging silica nanoparticles upon transfer into A549 (human lung cancer) cells. The nanoparticles were prepared at different concentrations $(0.1-1 \mathrm{mg} /$ 


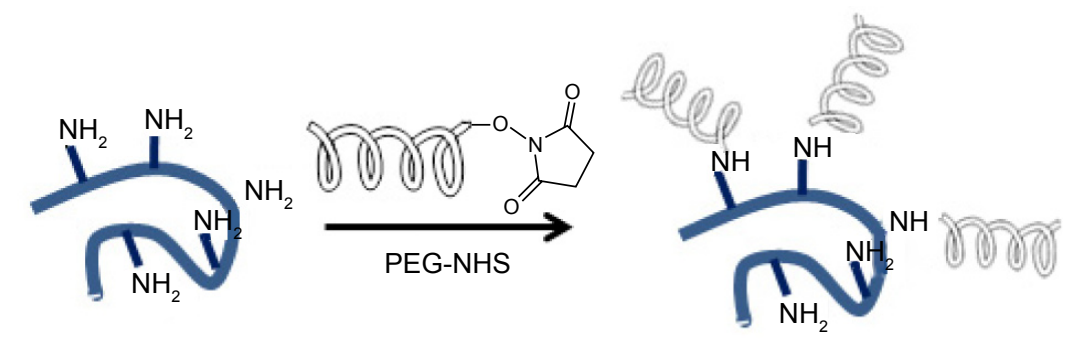

Pegylated PEI

TPS
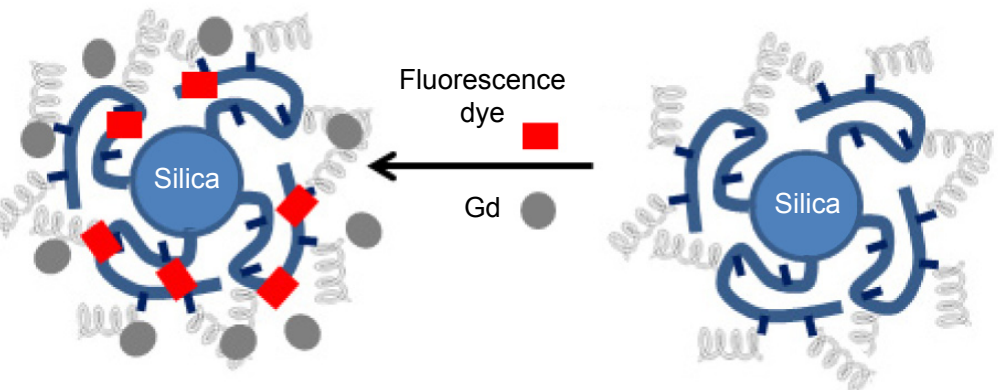

Figure I Synthesis of dual imaging silica nanoparticles.

Abbreviations: Gd, gadolinium; NHS, N-hydroxysuccinate; PEG, poly(ethylene glycol); PEl, polyethylenimine; TPS, trimethoxy(3-[oxiran-2-ylmethoxy]propyl)silane.

A

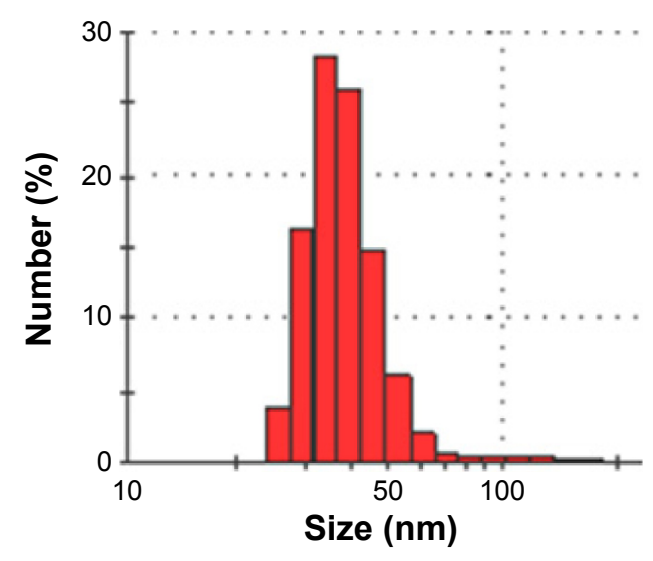

C

\begin{tabular}{|l|l|l|l|}
\hline $\begin{array}{l}\text { Element } \\
\text { weight }\end{array}$ & Weight \% & $\begin{array}{l}\text { Weight \% } \\
\text { sigma }\end{array}$ & $\begin{array}{l}\text { Atomic } \\
\text { weight \% }\end{array}$ \\
\hline $\mathrm{O}_{\mathrm{K}}$ & 46.23 & 1.33 & 62.01 \\
$\mathrm{Si}_{\mathrm{K}}$ & 48.85 & 1.31 & 37.32 \\
$\mathrm{Gd}_{\mathrm{L}}$ & 4.92 & 1.37 & 0.67 \\
Total & 100 & & \\
\hline
\end{tabular}
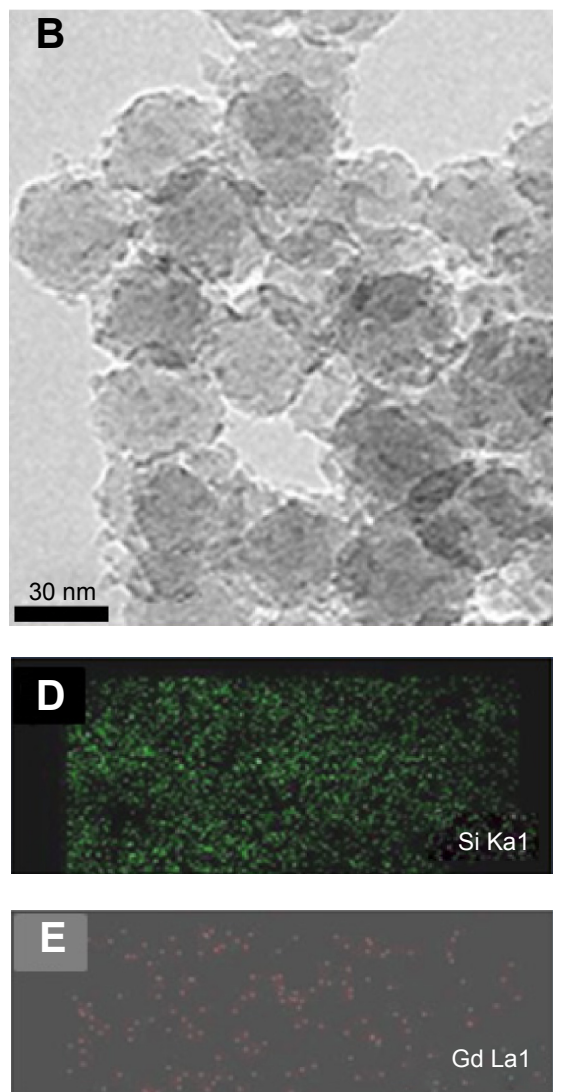

Figure 2 (A) Particle size distribution (by dynamic light scattering) and (B) morphological analysis (by transmission electron microscopy) of Gd silica nanoparticles, (C) energy-dispersive spectroscopic elemental analysis, and the corresponding elemental mapping of Si (D) and Gd (E).

Abbreviations: Si, silica; Gd, gadolinium. 

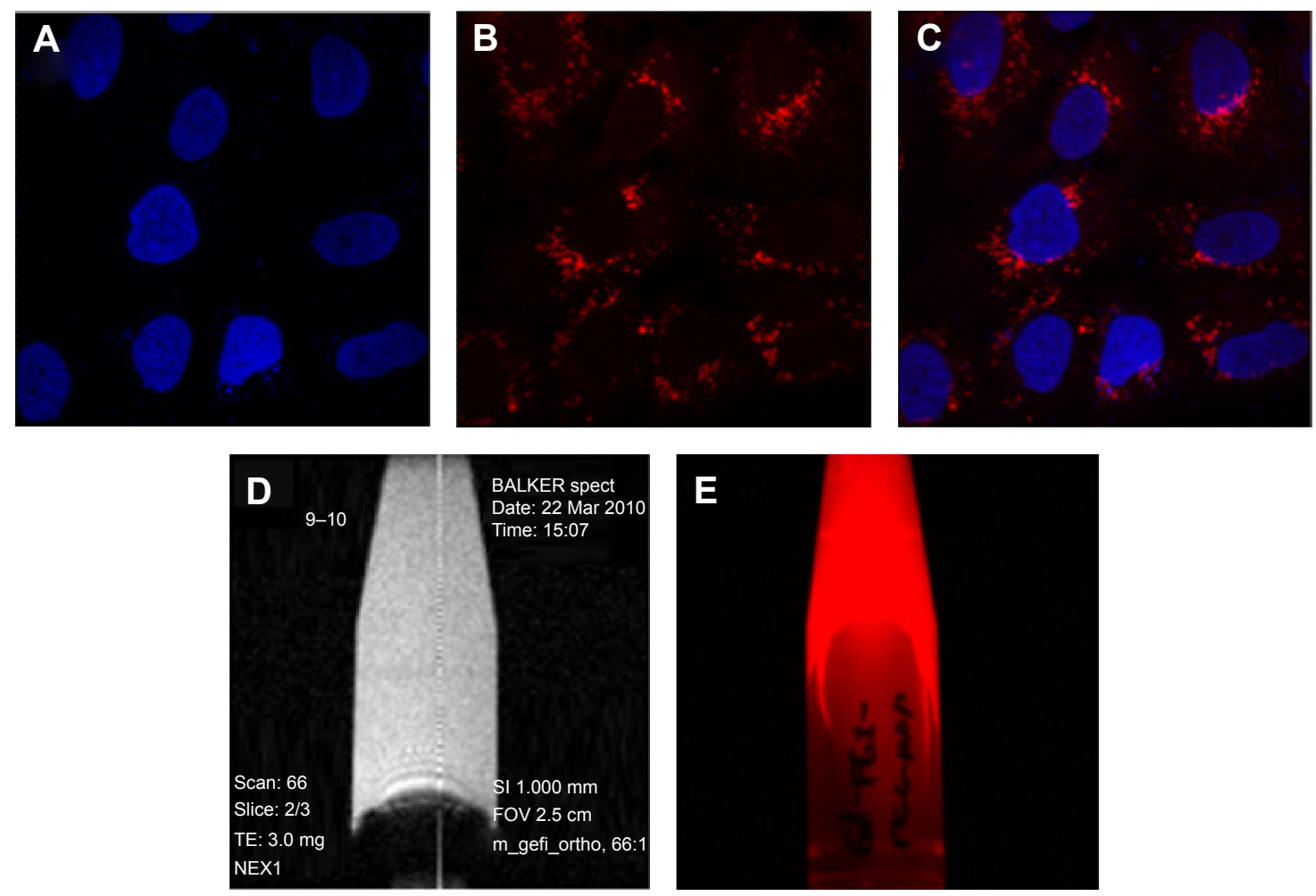

Figure 3 (A-C) Feasibility of cell transfection in A549 lung cancer cells in fluorescent imaging mode using gadolinium-conjugated silica nanoparticles (0.2 mg/mL).

Notes: (A) Nuclei stained by 4,6-diamidino-2-phenylindole (blue), (B) dual imaging silica nanoparticles represents red fluorescence (rhodamine isothiocyanate dye). (C) Merged fluorescence microscopic image of dual imaging silica nanoparticles transfected in A549 lung cancer cells. Gadolinium-conjugated silica nanoparticles in colloidal solution using $T_{1}$-weighted magnetic resonance imaging $(\mathbf{D})$ and fluorescent imaging mode $(\mathbf{E})$.

$\mathrm{mL}$ ) and transfected into the wells dropwise. After incubation for 4 hours, the old medium was replaced by fresh medium, and the nanoparticle-treated cells were incubated for 24 hours. The nucleus was stained with DAPI (blue), and the dual imaging silica nanoparticles showed red fluorescence (Figure $3 \mathrm{~A}-\mathrm{C}$ ). Figure 3D shows the T1-weighted MR imaging for the colloidal silica solution produced by a microimaging analyzer (9.4 T). In addition, the dual imaging silica nanoparticles had red fluorescence functionality (Figure 3E). Atul et al have reported that the surface charge on nanoparticles can affect cellular localization, and shown that positively charged nanoparticles demonstrate significant uptake in A549 lung cancer cells when compared with negatively charged nanoparticles. ${ }^{60}$ Our dual imaging silica nanoparticles had a strong positive charge $(+50 \mathrm{mV}$, Figure S2). In agreement with Atul et al our positively charged dual imaging silica nanoparticles were easily transfected into A549 lung cancer cells.

The longitudinal $\left(\mathrm{r}_{1}\right)$ MR relaxivity for dual imaging silica nanoparticles was measured (Figure 4A). In addition, each $T_{1}$ relaxation time is shown in Figure 4B. High-resolution MR imaging was carried out using a Bruker vertical spectrometer (wide-bore, 9.4 T, 400.2 MHz). Gradient echo sequences were used to acquire the MR images (effective spectral bandwidth $101010.1 \mathrm{~Hz}$, echo time 3.000 milliseconds, echo position $50 \%$, repetition time 100.000 milliseconds) in order to compare all the samples (with a fixed receiver gain value of 370.0). A $128 \times 128$ acquisition matrix was used for a field of view. The total scan time measured was 125,800 milliseconds in one accumulation experiment. For the $\mathrm{T}_{1}$ measurements, the echo time was regulated at $79.225,125,250,500,750$, $1,000,2,000$, and 3,000 milliseconds. The echo time was 3.640 milliseconds. The field of view was the same as on the two-dimensional image. In the estimated total scan time, it has taken 0 hour 16 minutes 26 seconds 140 milliseconds. The dwell time was 0.004950 milliseconds and the minimum repetition time was 16.685 milliseconds. Relaxivity measurements were acquired by taking the slope of a plot of $1 /$ $\mathrm{T}_{1}\left(\mathrm{~s}^{-1}\right)$ versus concentration $(\mathrm{mM})$. The longitudinal water proton relaxation times $\left(\mathrm{T}_{1}\right)$ were determined using $400 \mathrm{MHz}$ solid-state NMR with a Bruker micro-imaging probe analyzer operating at $400 \mathrm{MHz}$ and $25^{\circ} \mathrm{C}$.

Interestingly, the relaxivity was higher $\left(r_{1}=9.41 \pm 0.32\right.$ $\mathrm{mM}^{-1} \mathrm{~s}^{-1}$ ) when compared with a previous report for a $\mathrm{T}_{1}$ Gd agent $\left(\mathrm{r}_{1}=3 \mathrm{mM}^{-1} \mathrm{~s}^{-1}\right){ }^{61}$ We used ICPMS to determine our $\mathrm{Gd}$ ion concentration, and $\mathrm{T}_{1}$ relaxivity was measured and compared using four different concentrations. 

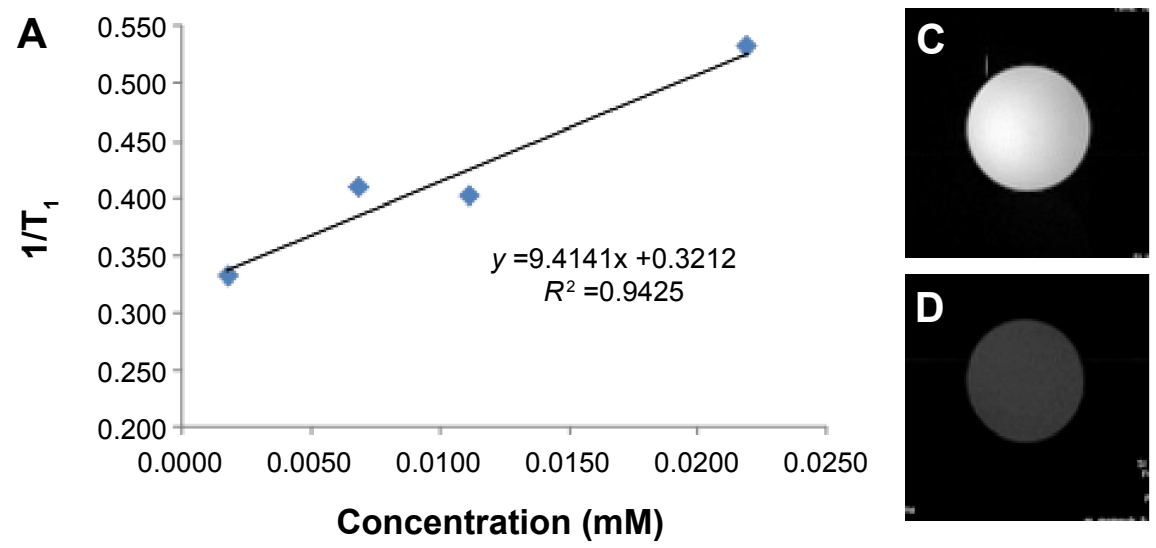

B

\begin{tabular}{|l|l|l|l|}
\hline $\mathbf{G d}^{3+}(\mathbf{m M})$ & $\mathbf{1 / T _ { 1 }}$ & $\mathbf{T}_{\mathbf{1}}$ (seconds) & Milliseconds \\
\hline 0.0219 & 0.532 & 1.87802 & $1,878.02$ \\
0.0111 & 0.402 & 2.48731 & $2,487.31$ \\
0.0068 & 0.410 & 2.44177 & $2,441.77$ \\
0.0017 & 0.332 & 3.00935 & $3,009.35$ \\
\hline
\end{tabular}

Figure 4 (A, B) Relaxation $\left(r_{1}\right)$ rates with different concentrations of dual imaging silica nanoparticles and $\left(\mathbf{C}\right.$, D) $T_{1}$-weighted images using a 9.4 T micro-imaging analyzer instrument. Colloidal solution of dual imaging silica nanoparticles in water (C) and a pure water sample (D).

Two-dimensional images were obtained using dual imaging silica nanoparticle dispersion (Figure 4C) and pure deionized water (Figure 4D) for comparison. Significant signal enhancement in the $\mathrm{T}_{1}$-weighted image was observed for the dual imaging silica nanoparticle dispersion. We believe that the highly hydrophilic environment of the dual imaging silica nanoparticles allows for easy access of water molecules to the Gd (III) ion for water proton relaxation. ${ }^{62-65}$ $\mathrm{Kim}$ et al reported on the use of Gd-TSPETE-silica nanoparticle-[Ru(bpy)3 $]^{2+}\left(r_{1}=9 \mathrm{mM}^{-1} \mathrm{~s}^{-1}\right) .{ }^{64}$ Therefore, the $\mathrm{r}_{1}$ relaxivity value for our Gd-PEI-PEG silica nanoparticles is similar to that of other silica nanoparticle-based MR imaging agents.

Information on the in vivo distribution of dual mode nanoparticles is useful for bioimaging purposes. Figure 5 compares the biodistribution imaging results at 1 hour and 6 hours after intraperitoneal injection of the nanoparticles. One hour after injection, rich storage was not observed in the pancreas; however, 6 hours after injection, Gd ions were accumulated primarily in the pancreas rather than in other organs such as liver, kidney, lung, pancreas, and spleen. Although Gd enrichment was observed in pancreas, broad distribution in all organs was clear. The circulation time and activity of nanoparticles in blood vessels can be enhanced by surface PEGylation. Our dual imaging silica nanoparticles utilized a PEGylation strategy and consequently showed broad biodistribution in all organs in a mouse model. We believe that the enhanced hydrophilicity of the PEGylated surface on the dual imaging silica nanoparticles increased the particle circulation time. Consequently, broad distribution of Gd was achieved in vivo. ${ }^{55-58}$

\section{Conclusion}

In summary, we used covalent bonding to construct nanoparticles with both MR imaging and fluorescence functionalities. Our Gd-decorated hybrid silica nanoparticles had highly enhanced MR relaxivity. In addition, optical imaging by fluorescence was achieved due to the surface-layered dyes. The polyamine and polycarboxyl groups increased the chelation efficiency of these Gd-silica nanoparticles. We believe that this protocol can be used to develop other useful bioimaging and theranostic silica hybrids for in vivo and in vitro biomedical applications. In the near future, we will report on our in vivo imaging research efforts to enhance the targeting ability of these conjugated hybrid silica nanoparticles. 


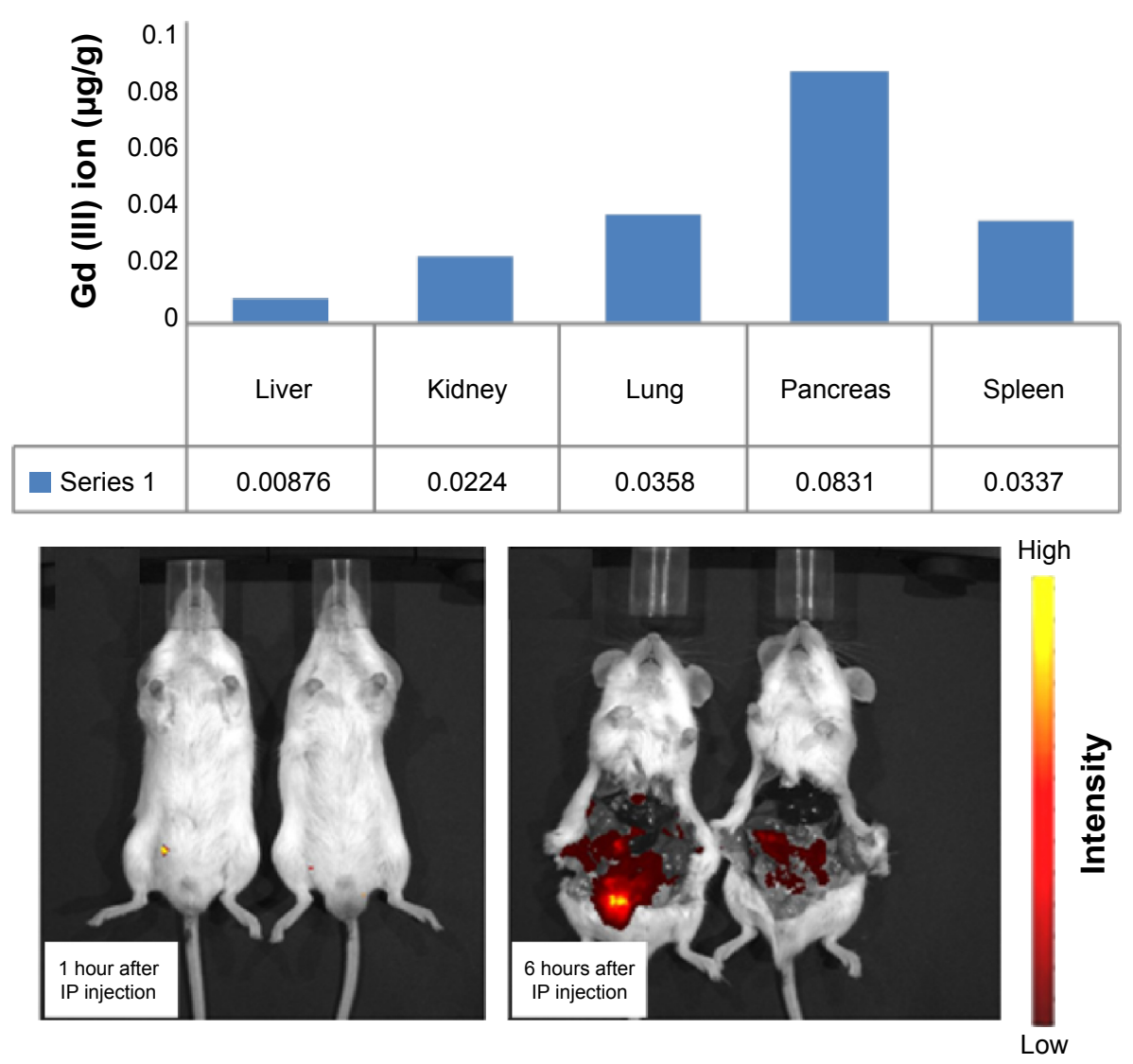

Figure 5 Distribution of gadolinium to the organs in an in vivo mouse model. The upper panel shows organ-dependent inductively coupled plasma mass spectrometry data 6 hours after injection. The lower panel shows the corresponding data at I hour and 6 hours after injection.

Abbreviations: IP, Intraperitoneal; Gd, gadolinium.

\section{Acknowledgment}

This work was supported by the 2015 Myongji University

Research Fund.

\section{Disclosure}

The authors report no conflicts of interest in this work.

\section{References}

1. Wienmann HJ, Brasch RC, Press WR, Wesbey GE. Characteristics of gadolinium-DTPA complex: a potential NMR contrast agent. AJR Am J Roentgenol. 1984;142:619-624.

2. Ulbrich $\mathrm{W}$, Lamprecht A. Targeted drug-delivery approaches by nanoparticulate carriers in the therapy of inflammatory diseases. $J R$ Soc Interface. 2009;7:55-66.

3. Ke JH, Lin JJ, Carey JR, Chen JS, Chen CY, Wang LF. A specific tumortargeting magnetofluorescent nanoprobe for dual-modality molecular imaging. Biomaterials. 2010;31:1707-1715.

4. Allouche J, Boissiere M, Helary C, Livage J, Coradin T. Biomimetic core-shell gelatin/silica nanoparticles: a new example of biopolymerbased nanocomposites. J Mater Chem. 2006;30:3120-3125.

5. Huang CC, Huang W, Su CH, Feng CN, Kuo WS, Yeh CS. A general approach to silicate nanoshells: gadolinium silicate and gadolinium silicate: europium nanoshells for dual-modality optical and MR imaging. Chem Commun. 2009;23:3360-3362.

6. Yu YY, Chen CY, Chen WC. Synthesis and characterization of organicinorganic hybrid thin films from poly(acrylic) and monodispersed colloidal silica. Polymer. 2003;44:593-601.
7. Borrego T, Andrade M, Pinto ML, et al. Physicochemical characterization of silylated functionalized materials. J Colloid Interface Sci. 2010; 344:603-610.

8. Salon MC, Gerbaud G, Abdelmouleh M, Bruzzese C, Boufi S, Belgacem MN. Studies of interactions between silane coupling agents and cellulose fibers with liquid and solid-state NMR. Magn Reson Chem. 2007;45:473-483.

9. Kleemann E, Neu M, Jekel N, et al. Nano-carriers for DNA delivery to the lung based upon a TAT-derived peptide covalently coupled to PEG-PEI. J Control Release. 2005;109:209-316.

10. Fuller JE, Zugates GT, Ferreira LS, et al. Intracellular delivery of core-shell fluorescent silica nanoparticles. Biomaterials. 2008;29:1526-1532.

11. Mijatovic J, Binder WH, Gruber H. Characterization of surface modified silica nanoparticles by ${ }^{29} \mathrm{Si}$ solid state NMR spectroscopy. Mikrochim Acta. 2000;133:175-181.

12. Peer D, Karp JM, Hong S, Farokhzad OC, Margalit R, Langer R. Nanocarriers as an emerging platform for cancer therapy. Nat Nanotechnol. 2007;2:751-760

13. Lipski AM, Pino CJ, Haselton FR, Chen IW, Shastri VP. The effect of silica nanoparticle-modified surfaces on cell morphology cytoskeletal organization and function. Biomaterials. 2008;29:3836-3846.

14. Santra S, Zhang P, Wang K, Tapec R, Tan W. Conjugation of biomolecules with luminophore-doped silica nanoparticles for photostable biomarkers. Anal Chem. 2001;73:4988-4993.

15. Feng L, Wang Y, Wang N, Ma Y. Preparation of poly(ethylene glycol)grafted silica nanoparticles using a facile esterification condensation method. Polym Bull. 2009;63:313-327.

16. Joubert M, Delaite C, Bourgeat-Lami E, Dumas P. Hairy PEO-silica nanoparticles through surface-initiated polymerization of ethylene oxide. Macromol Rapid Commun. 2005;26:602-607. 
17. Estevez MC, O’Donghue MB, Chen XT. Highly fluorescent dye-doped silica nanoparticles increase flow cytometry sensitivity for cancer cell monitoring. Nano Res. 2009;2:448-461.

18. Graf C, Vossen DLJ, Imhof A, Blaaderen AV. A general method to coat colloidal particles with silica. Langmuir. 2003;19:6693-6700.

19. Kim JS, Rieter WJ, Taylor KM, An H, Lin W, Lin W. Self-assembled hybrid nanoparticles for cancer-specific multimodal imaging. $J \mathrm{Am}$ Chem Soc. 2007;129:8962-8963.

20. Mishra R, Su W, Pohmann R, et al. Cell-penetrating peptides and peptide nucleic acid-coupled MRI contrast agents: evaluation of cellular delivery and target binding. Bioconjug Chem. 2009;20:1860-1868.

21. Shin J, Adnisur RM, Ko MK, Im GH, Lee JH, Lee IS. Hollow manganese oxide nanoparticles as multifunctional agents for magnetic resonance imaging and drug delivery. Angew Chem Int Ed. 2009;48:321-324.

22. Yi DK, Lee SS, Papaefthymiou GC, Ying JY. Nanoparticle architectures template by $\mathrm{SiO}_{2} / \mathrm{Fe}_{2} \mathrm{O}_{3}$ nanocomposites. Chem Mater. 2005;18: 614-619.

23. Uecker M, Zhang S, Voit D, Karaus A, Merboldt KD, Frahm J. Realtime MRI at a resolution of $20 \mathrm{~ms}$. NMR Biomed. 2010;23:986-994.

24. Smrnov P, Gazeau F, Beloeil JC, Doan BT, Wilhelm C, Gillet B. Single-cell detection by gradient echo 9.4T MRI: a parametric study. Contrast Med Mol Imaging. 2006;1:165-174.

25. Liong M, Lu J, Kovochich M, et al. Multifunctional inorganic nanoparticles for imaging, targeting, and drug delivery. ACS Nano. 2008;2: 889-896.

26. Selvan S, Tan TT, Yi DK, Jana NR. Functional and multifunctional nanoparticles for bioimaging and biosensing. Langmuir. 2010;26: 11631-11641.

27. Gindy ME, Prud'homme RK. Multifunctional nanoparticles for imaging, delivery and targeting in cancer therapy. Expert Opin Drug Deliv. 2009;6:865-878.

28. Mackay JA, Chen M, McDaniel JR, Liu W, Simnick AJ. Self-assembling chimeric polypeptide-doxorubicin conjugate nanoparticles that abolish tumors after a single injection. Nat Mater. 2009;8:993-999.

29. Budde MD, Frank JA. Magnetic tagging of therapeutic cells for MRI. J Nucl Med. 2009;50:171-174.

30. Barge A, Cravotto G, Gianolio E, Fedeli F. How to determine free Gd and free ligand in solution of $\mathrm{Gd}$ chelates. A technical note. Contrast Med Mol Imaging. 2006;1:184-188.

31. Hillaireau H, Couvreur P. Nanocarriers' entry into the cell: relevance to drug delivery. Cell Mol Life Sci. 2009;66:2873-2896.

32. Korzeniowska B, Nooney R, Wencel D, McDonagh C. Silica nanoparticles for cell imaging and intracellular seeding. Nanotechnology. 2013; 24:2002.

33. Brannon-Peppas L, Blanchette JO. Nanoparticle and targeted systems for cancer therapy. Adv Drug Deliv Rev. 2004;56:1649-1659.

34. Lessard-Viger M, Rioux M, Rainville L, Boudreau D. FRET-enhancement in multilayer core-shell nanoparticles. Nano Lett. 2009;9:3066-3071.

35. Park H, Yang J, Lee J, Haam S, Choi IH, Yoo KH. Multifunctional nanoparticles for combined doxorubicin and photothermal treatments. ACS Nano. 2009;3:2919-2926.

36. Bardhan BR, Chen W, Perez-Torres C, et al. Nanoshells with targeted simultaneous enhancement of magnetic and optical imaging and photothermal therapeutic response. Adv Funct Mater. 2009;19: 3901-3909.

37. Law B, Tung CH. Proteolysis: a biological process adapted in drug delivery, therapy, and imaging. Bioconjug Chem. 2009;20:1683-1695.

38. Chong HS, Song HA, Lim S, et al. A novel cholic acid-based contrast enhancement agent for targeted MRI. Bioorg Med Chem Lett. 2008;18: 2505-2508

39. Kamaly N, Kalber T, Thanou M, Bell JD, Miller AD. Folate receptor targeted bimodal liposomes for tumor magnetic resonance imaging. Bioconjug Chem. 2009;20:648-655.

40. Al-Ogaidi I, Gou H, Al-Kazaz AK, et al. A gold@silica core-shell nanoparticle-based surface-enhanced Raman scattering biosensor for label-free glucose detection. Anal Chim Acta. 2014;811:76-80.
41. Richard C, Doan BT, Beloeil JC, Bessodes M, Toth E, Scherman D. Noncovalent functionalization of carbon nanotubes with amphiphilic $\mathrm{Gd} 3+$ chelates: toward powerful $\mathrm{T}_{1}$ and $\mathrm{T}_{2} \mathrm{MRI}$ contrast agents. Nano Lett. 2008;8:232-236.

42. Hirai M, Minematsu H, Kondo N, Oie K, Igarashi K, Yamazaki N. Accumulation of liposome with sialyl Lewis $\mathrm{X}$ to inflammation and tumor region: application to in vivo bio-imaging. Biochem Biophys Res Commun. 2007;353:553-558.

43. Wangler C, Moldenhauer G, Saffrich R, et al. PAMAM structure-based multifunctional fluorescent conjugates for improved fluorescent labeling of biomacromolecules. Chem Eur J. 2008;14:8116-8130.

44. Fletcher S, Jorgensen MR, Miller AD. Facile preparation of an orthogonally protected, $\mathrm{pH}$-sensitive, bioconjugate linker for therapeutic applications. Org Lett. 2004;6:4245-4248.

45. Major JL, Meade TJ. Bioresponsive, cell-penetrating, and multimeric MR contrast agents. Acc Chem Res. 2009;42:893-903.

46. Thian YL, Riddell AM, Koh DM. Liver-specific agents for contrastenhanced MRI: role in oncological imaging. Cancer Imaging. 2013;13: 567-579.

47. Yoon TJ, Yu KN, Kim E, et al. Specific targeting, cell sorting, and bioimaging with smart magnetic silica core-shell nanomaterials. Small. 2006;2:209-215.

48. Cheng W, Ping Y, Zhang Y, Chuang KH, Liu Y. Magnetic resonance imaging (MRI) contrast agents for tumor diagnosis. $J$ Healthc Eng. 2013;4:23-45

49. Yi DK, Selvan ST, Lee SS, Papaefthymiou GC, Kundaliya D, Ying JY. Silica-coated nanocomposites of magnetic nanoparticles and quantum dots. J Am Chem Soc. 2005;127:4991-4992.

50. Cai J, Shapiro EM, Hamilton AD. Self-assembling DNA quadruplex conjugated to MRI contrast agents. Bioconjug Chem. 2009;20:205-208.

51. Tsai CP, Hung Y, Chou YH, et al. High-contrast paramagnetic fluorescent mesoporous silica nanorods as a multifunctional cell-imaging probe. Small. 2008;4:186-191.

52. Louie A. Multimodality imaging probes: design and challenges. Chem Rev. 2010;110:3146-3195.

53. He Q, Zhang J, Shi Ja, et al. The effect of PEGylation of mesoporous silica nanoparticles on nonspecific binding of serum proteins and cellular responses. Biomaterials. 2010;31:1085-1092.

54. Cho J, Char K, Hong JD, Lee KB. Fabrication of highly ordered multilayer films using a spin self-assembly method. Adv Mater. 2001;13: 1076-1078

55. Du L, Chen J, Qi Y, et al. Preparation and biomedical application of nonpolymer coated superparamagnetic nanoparticles. Int J Nanomedicine. 2007;2:805-812.

56. Taupitz M, Schnorr J, Mjuk A. New generation of monomer stabilized very small superparamagnetic iron oxide particles (VSOP) as contrast medium for angiography: preclinical results in rats and rabbits. J Magn Reson Imaging. 2000;12:905-911.

57. Schnorr J, Wagner S, Pilgrimm H. Preclinical characterization of monomer-stabilized very small superparamagnetic iron oxide particles (VSOP) as a blood pool contrast medium for MR angiography. Acad Radiol. 2002;2:S307-S309.

58. Wagner S, Schnorr J, Pilgrimm H. Monomer-coated very small superparamagnetic iron oxide particles as contrast medium for magnetic resonance imaging: preclinical in vivo characterization. Invest Radiol. 2002;37:167-177.

59. Chang CA, Brittain HG, Telser J, Tweedle MF. pH dependence of relaxivities and hydration numbers of gadolinium(III) complexes of linear amino carboxylates. Inorg Chem. 1992;31:5597-5600.

60. Asati A, Santra S, Kaittanis CS, Perez MJ. Surface-charge-dependent cell localization and cytotoxicity of cerium oxide nanoparticles. ACS Nano. 2010;4:5321-5331.

61. Haar PJ, Broaddus WC, Chen ZJ, Fatouros PP, Gillies GT, Corwin FD. Gd-DTPA T1 relaxivity in brain tissue obtained by convection-enhanced delivery, magnetic resonance imaging and emission spectroscopy. Phys Med Biol. 2010;55:3451-3465. 
62. Boiteau R, Meade T, Major J. Gadolinium-labeled nanoparticles for magnetic resonance imaging. Nanoscape. 2008;5:33-39.

63. Davis JJ, Huang WY, Davies GL. Location-tuned relaxivity in Gd-doped mesoporous silica nanoparticles. J Mater Chem. 2012;22:22848-22850.

64. Kim JY, Piao Y, Hyeon TH. Multifunctional nanostructured materials for multimodal imaging, and simultaneous imaging and therapy Chem Soc Rev. 2009;38:372-390.
65. Wartenberg N, Fries P, Raccurt O, Guillermo A, Imbert D, Mazzanti M. A gadolinium complex confined in silica nanoparticles as a highly efficient $\mathrm{T}_{1} / \mathrm{T}_{2}$ MRI contrast agent. Chemistry. 2013;9:6980-6983. 


\section{Supplementary materials}

In order to provide more detailed characterization, solid-state nuclear magnetic resonance (NMR) analyses were performed, $600 \mathrm{MHz}{ }^{1} \mathrm{H}-\mathrm{NMR}$ spectrum and $400 \mathrm{MHz}{ }^{29} \mathrm{Si},{ }^{13} \mathrm{C}$ CP MAS NMR spectrum. (A) ${ }^{29} \mathrm{Si}$ CP MAS NMR spectrum of aminopropyl-functionalized silica nanoparticles and PEI 25,000-PEG 5,000 graft silica nanoparticles were compared with silica nanoparticles. (B) ${ }^{13} \mathrm{C} \mathrm{CP}$ MAS NMR spectrum of aminopropyl-functionalized silica nanoparticles and PEI 25,000-PEG 5,000 graft silica nanoparticles were also compared with silica nanoparticles. (C) $600 \mathrm{MHz}{ }^{1} \mathrm{H}-\mathrm{NMR}$ NMR spectra are shown for PEI 25,000, PEG 5,000, and PEI 25,000-PEG 5,000 copolymer.

Solid-state ${ }^{29} \mathrm{Si}$ CP-MAS NMR analyses were performed using a Bruker Avance $400 \mathrm{MHz}$ spectrometer operating at $79.545 \mathrm{MHz}$. The samples were located in $4 \mathrm{~mm} \mathrm{ZrO}_{2}$ rotors.
A

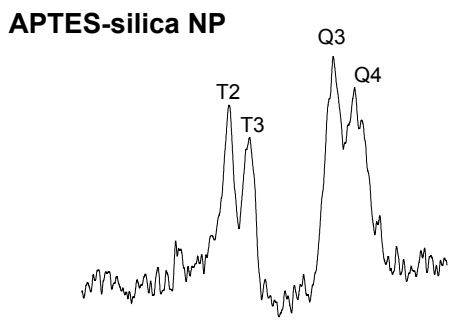

PEI 25k-PEG 5k-silica NP

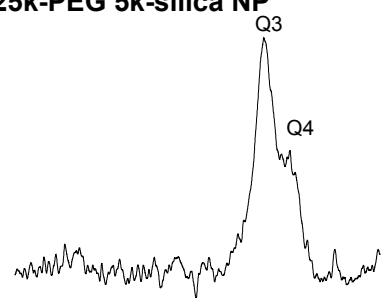

Silica NP

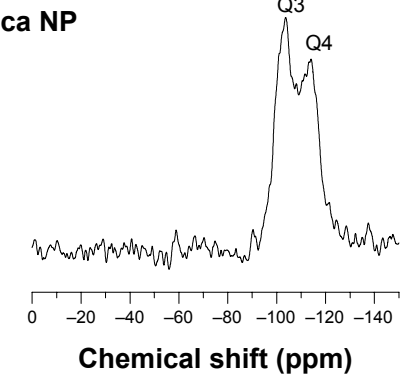

B
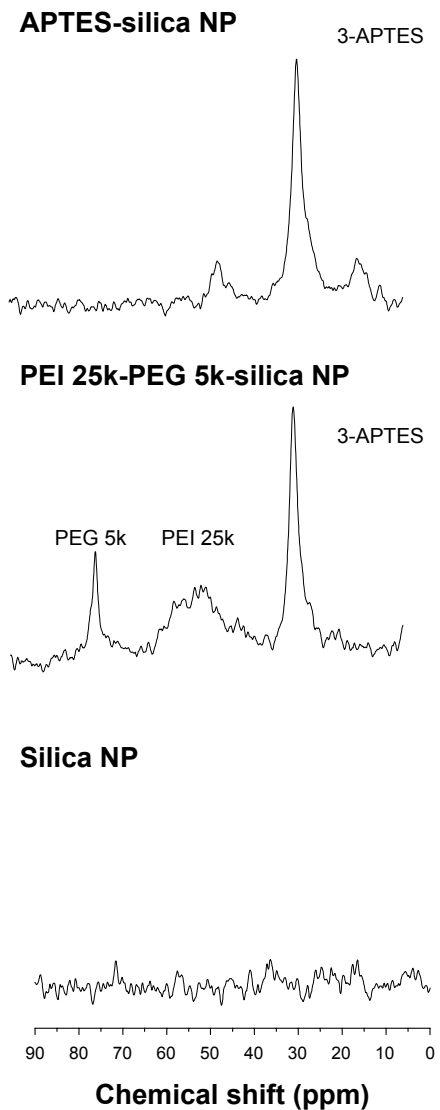

C



PEG 5k

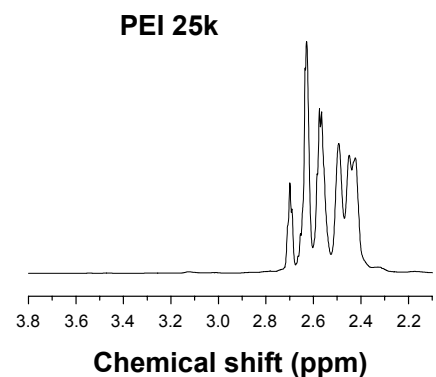

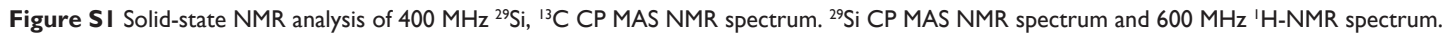

Notes: ${ }^{29} \mathrm{Si} C P$ MAS NMR spectrum of aminopropyl functionalized silica nanoparticles and PEI 25 -PEG $5 \mathrm{k}$ graft silica nanoparticles as well as silica nanoparticles $(\mathbf{A})$, ${ }^{13} \mathrm{C} C P$ MAS NMR spectrum of aminopropyl functionalized silica nanoparticles and PEI 25-PEG 5k graft silica nanoparticles as well as silica nanoparticles (B), 600 MHz 'H-NMR NMR spectrum of PEI 25k, PEG5k as well as PEI 25k-PEG 5k copolymer (C).

Abbreviations: APTES, (3-aminopropyl)triethoxysilane; NP, nanoparticle; PEG, poly(ethylene glycol); PEl, polyethylenimine; Ppm, parts per million, NMR, nuclear magnetic resonance.

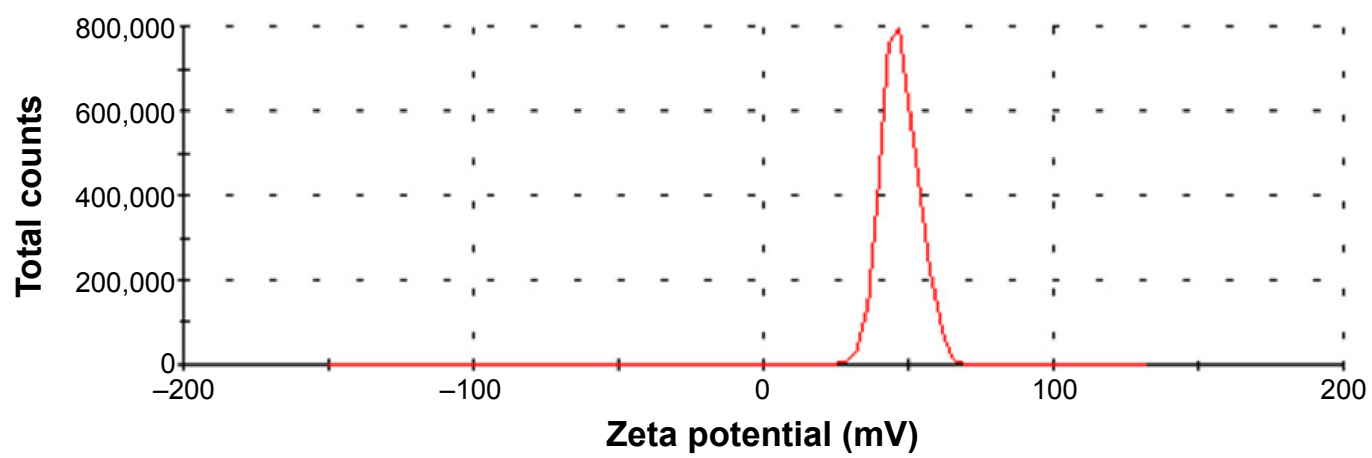

Figure S2 Zeta potential of the dual imaging silica nanoparticles. 
Magic angle spinning was carried out at a spinning rate of $7 \mathrm{kHz}$. The spectrum width was $23.8 \mathrm{kHz}$, and the delay or repetition time was 5.0 seconds. Contact time was performed for 5 milliseconds. The ${ }^{29} \mathrm{Si}$ spectrum was calibrated with the signal obtained using the external standard DSS [3-(trimethylsilyl)-1-propane sulfonic acid, sodium salt 97\%, Sigma Chemicals] at $0.00 \mathrm{ppm}$.
The ${ }^{13} \mathrm{C}$ solid-state NMR experiments were performed with the same NMR instrument, ie, ${ }^{29} \mathrm{Si}$ CP-MAS NMR operating with $100.690 \mathrm{MHz}$. $\mathrm{ZrO}_{2}$ rotors (4 mm) were used, and magic angle spinning was carried out at a spinning rate of $7 \mathrm{kHz}$, a $30.3 \mathrm{kHz}$ spectrum width, a 5.0 seconds delay or repetition time, and a 2 milliseconds contact time.

\section{Publish your work in this journal}

The International Journal of Nanomedicine is an international, peerreviewed journal focusing on the application of nanotechnology in diagnostics, therapeutics, and drug delivery systems throughout the biomedical field. This journal is indexed on PubMed Central,

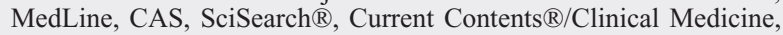

Journal Citation Reports/Science Edition, EMBase, Scopus and the Elsevier Bibliographic databases. The manuscript management system is completely online and includes a very quick and fair peer-review system, which is all easy to use. Visit http://www.dovepress.com/ testimonials.php to read real quotes from published authors. 